\title{
Congenital Thyroid Gland Aplasia
}

National Cancer Institute

\section{Source}

National Cancer Institute. Congenital Thyroid Gland Aplasia. NCI Thesaurus. Code C27112.

Absence of the thyroid gland in a newborn. 